\title{
Spectrofluorimetric Determination of Aliskiren in Tablets and Spiked Human Plasma through Derivatization with Dansyl Chloride
}

\author{
Zeynep Aydoğmuș • Ferhat Sarı • Sevgi Tatar Ulu
}

Received: 20 January 2011 / Accepted: 19 September 2011 / Published online: 29 September 2011

(C) The Author(s) 2011. This article is published with open access at Springerlink.com

\begin{abstract}
A simple and sensitive method has been developed and validated for the determination of aliskiren (ALS) in its dosage forms and spiked plasma. The method was based on the reaction of the drug with dansyl chloride in the presence of bicarbonate solution of $\mathrm{pH} 10.5$ to give a highly fluorescent derivative which was measured at $501 \mathrm{~nm}$ with excitition at $378 \mathrm{~nm}$ in dichloromethane. Different experimental parameters affecting the development of the method and stability were carefully studied and optimized. The calibration curves were linear over the concentration ranges of 100-700 and 50$150 \mathrm{ng} / \mathrm{mL}$ for standard solution and plasma, respectively. The limits of detection were $27.52 \mathrm{ng} / \mathrm{mL}$ in standard solution, $4.91 \mathrm{ng} / \mathrm{mL}$ in plasma. The developed method was successfully applied to the analysis the drug in the commercial tablets and spiked plasma samples. The mean recovery of ALS from tablets and plasma was 100.10 and $97.81 \%$, respectively. A proposal of the reaction pathway was presented.
\end{abstract}

Keywords Aliskiren · Dansyl chloride .

Spectrofluorimetry $\cdot$ Tablets $\cdot$ Spiked plasma

\section{Introduction}

Aliskiren hemifumarate [(2S,4S,5S,7S)-N-(2-carbamoyl-2methyl propyl)-5-amino-4-hydroxy-2,7-diisopropyl-8-[4methoxy-3-(3-methoxypropoxy)phenyl]-octanamide hemifumarate] (ALS) is a direct renin enzym inhibitor and

\footnotetext{
Z. Aydoğmuș $(\bowtie) \cdot F$. Sarı $\cdot$ S. T. Ulu

Department of Analytical Chemistry, Faculty of Pharmacy, Istanbul University,

34116, Beyazıt,

Istanbul, Turkey

e-mail: zaydogmus@yahoo.com
}

recently has been approved for the treatment of essential hypertension [1-3].

There is no official analytical method for analysis of ALS. Literature survey revealed that a some analytical methods (mostly for investigation of pharmacokinetics properties of drug) for determination of ALS in serum and plasma have been reported. These methods include radioimmunoassay [4], heigh performance liquid chromatography (HPLC) [5], heigh performance liquid chromatography/mass spectrometry (HPLC/MS) [6-9], HPLC/MS/MS [1-3] detection. There are only two HPLC $[10,11]$ and a spectrophotometric methods [10] for the determination of the drug in pharmaceutical dosages. The HPLC coupled with mass spectrometry methods offered the required sensitivity for the analysis of ALS in biological fluids; however their sophisticated instrumentation and high analysis cost limited their use for analysis of drugs. The reported spectrophotometric and HPLC medhods for estimation of ALS in tablets [10] are not sensitive enough with the initial determined concentration of analyte ( 40 and $25 \mu \mathrm{g} / \mathrm{mL}$, respectively) and the method may not also apply to analysis of drug in biological fluids. Moreover, the validation results were not given in the reported HPLC method [10, 11]. Although, spectrofluorimetry is a sensitive, selective and simple technique, however up to now, no method has been reported for the determination of ALS in tablets and human plasma by spectrofluorimetry. For these reasons, and novelty of the drug, the development of new sensitive and simple spectrofluorimetric method is very essential. DNS-Cl is known to react with primary, secondary amines, imidazoles, thiols, phenolic and alcoholic hydroxyl groups and carboxylic acid groups [12-14]. DNS-Cl has been used as a fluorogenic reagent for the determination of many pharmaceutical compounds [15-17].

The present study describes a simple, sensitive, fast and cheap spectrofluorometric method for the analysis of ALS 
Table 1 The maximum excitation and emission wavelength of the ALS-DNS derivatization products in different organic extraction solvents. $[\mathrm{ALS}]=800 \mathrm{ng} / \mathrm{mL}$

\begin{tabular}{llc}
\hline Extraction Solvent & $\lambda_{\mathrm{ex}} / \lambda_{\mathrm{em}}(\mathrm{nm})$ & Fluorescence intensity \\
\hline Dichloromethane & $378 / 501$ & 918.419 \\
Chloroform & $381 / 494$ & 481.264 \\
Carbon tetrachloride & $372 / 497$ & 402.594 \\
Diethyl ether & $385 / 489$ & 356.814 \\
\hline
\end{tabular}

in its tablets and spiked plasma samples. The developed method was based on its reaction with dansyl chloride (DNS-Cl) in bicarbonate solution of $\mathrm{pH} 10.50$, to form fluorescent product which was measured fluorometrically at $501 \mathrm{~nm}\left(\lambda_{\mathrm{ex}} 378 \mathrm{~nm}\right)$.

\section{Experimental}

\section{Apparatus}

Shimadzu RF-1501 (Tokyo, Japan) spectrofluorometer and Shimadzu UV-160 (Tokyo, Japan) UV-vis spectrophotometer were used. One centimeter path length quartz cells were used. $\mathrm{pH}$ measurements were made with WTWpH 526 digital pH Meter.

Materials and Reagents

All reagents and solvents were of analytical reagent grade. ALS was kindly supplied by Novartis Pharmaceutical (Istanbul-Turkey) and its film-coated Tekturna ${ }^{\circledR}$ tablets containing $150 \mathrm{mg}$ and $300 \mathrm{mg}$ of ALS were obtained from local pharmacy in Chicago-USA. 5- dimethylaminonaphthalene-1sulphonyl chloride (DNS-Cl) purchased from Sigma-Aldrich (Germany). Solution of DNS-Cl was freshly prepared at $2.0 \mathrm{mg} / \mathrm{ml}$ in acetonitrile.

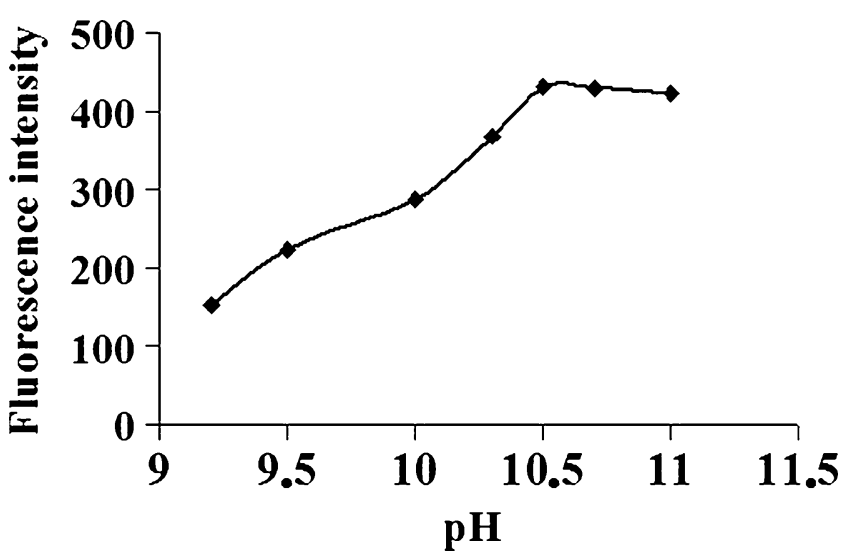

Fig. 1 Effect of the $\mathrm{pH}$ on the development of the reaction product of ALS $(800 \mathrm{ng} / \mathrm{mL})$ with DNS-Cl

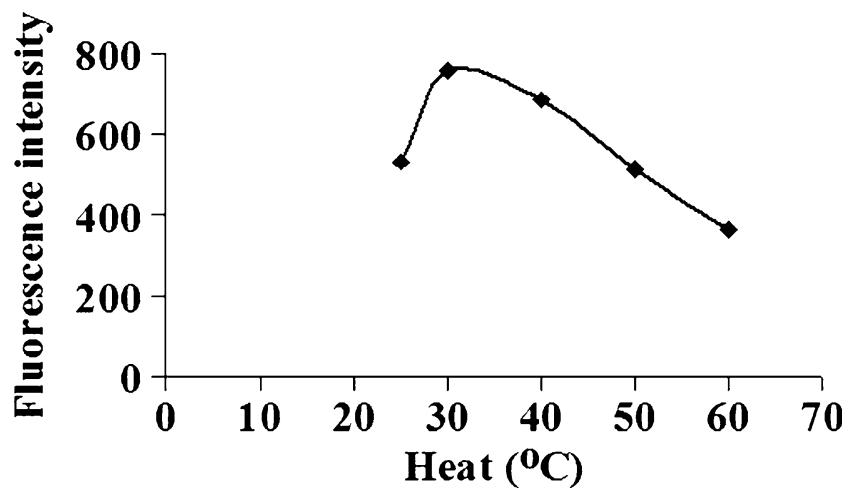

Fig. 2 Effect of temperature on the reaction of ALS $(800 \mathrm{ng} / \mathrm{mL})$ with DNS-Cl

The sodium bicarbonate $(0.025 \mathrm{M})$ solution was prepared in water and adjusted $\mathrm{pH}$ to 10.5 with $0.1 \mathrm{M}$ sodium hydroxide using a $\mathrm{pH}$ meter. This solution was kept in refrigerator and used for about 1 week.

Water was purified by aquaMAXTM-ultra, Young-lin instrument (Korea) ultrawater purification system.

Solutions

A stock solution at $1.0 \mathrm{mg} / \mathrm{mL}$ (concentration expressed as base compound) was prepared in water. This stock solution was further diluted with water to obtain standard solutions at $0.01 \mathrm{mg} / \mathrm{mL}$. The solutions were stable for at least one month when kept in the refrigerator.

General Procedures

\section{Procedure for Calibration Curve}

Aliquots of $50.0-350.0 \mu \mathrm{L}$ of standard drug solutions $(0.01 \mathrm{mg} / \mathrm{mL})$ were transferred into a series of $10 \mathrm{~mL}$ stoppered glass tubes. A $300 \mu \mathrm{L}$ of bicarbonate solution at $\mathrm{pH} 10.5$ and $300 \mu \mathrm{L}$ of DNS-Cl solution were added to each tube and the mixture was left for $20 \mathrm{~min}$ at $30^{\circ} \mathrm{C}$ in the dark. Then, the derivative was extracted with $5 \mathrm{~mL}$ of dichloro-

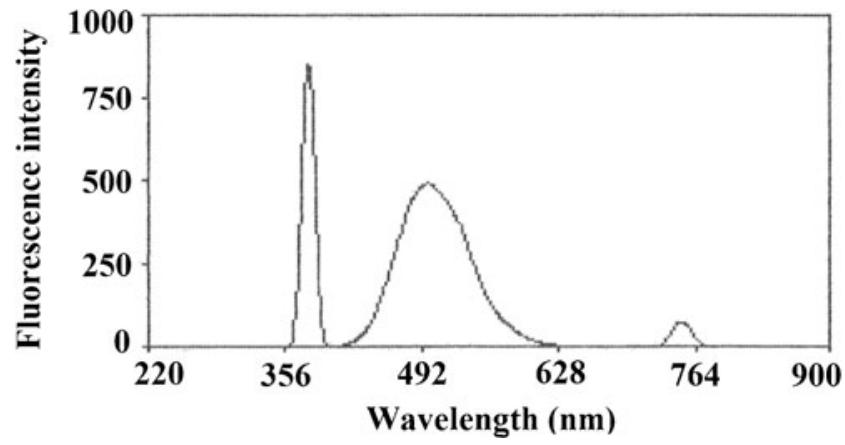

Fig. 3 Emission spectrum of the reaction product of ALS (350 ng/mL) with DNS-Cl $\left(\lambda_{\mathrm{ex}}=378 \mathrm{~nm}, \lambda_{\mathrm{em}}=501 \mathrm{~nm}\right)$ in dichloromethane 


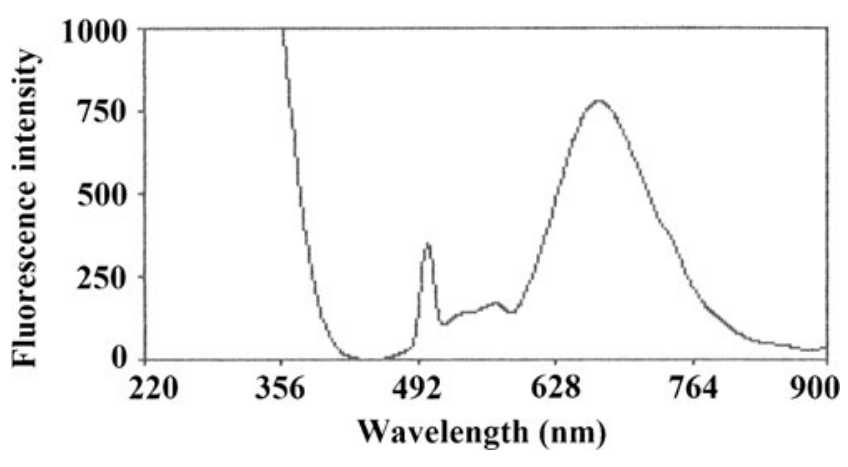

Fig. 4 Excitation spectrum of the reaction product of ALS (350 ng/ $\mathrm{mL})$ with DNS-Cl $\left(\lambda_{\mathrm{ex}}=378 \mathrm{~nm}, \lambda_{\mathrm{em}}=501 \mathrm{~nm}\right)$ in dichloromethane

methane by a vortex mixer. The organic layer was separated and dried over anhydrous sodium sulfate. The fluorescence intensity of the resulting solution was measured at $501 \mathrm{~nm}$ after excitation at $378 \mathrm{~nm}$. Blank experiment was carried out simultaneously. The corrected fluorescence intensity was plotted versus the final drug concentrations to get the calibration curve. The corresponding regression equation was derived.

\section{Procedure for Spiked Human Plasma}

Drug free human plasma was obtained from Istanbul University Cerrahpasa Hospital (Istanbul, Turkey) and stored at $-20{ }^{\circ} \mathrm{C}$ until analysis and thawed to room temperature before use. A $0.5 \mathrm{~mL}$ aliquot of human plasma was transferred into a series of centrifuge tubes and spiked with different concentration of ALS to give a final concentration range of $50-150 \mathrm{ng} / \mathrm{mL}$ (Table 1). Extraction with $1.0 \mathrm{~mL}$ acetonitrile was performed to precipitate plasma proteins, followed by centrifugation at 4,500 rpm for $20 \mathrm{~min}$. The resulting supernatant was evaporated to dryness under nitrogen at $40{ }^{\circ} \mathrm{C}$. The residual mass was reconstituted with $0.1 \mathrm{~mL}$ water and then the analyses were performed as under "Procedure for Calibration Curve".

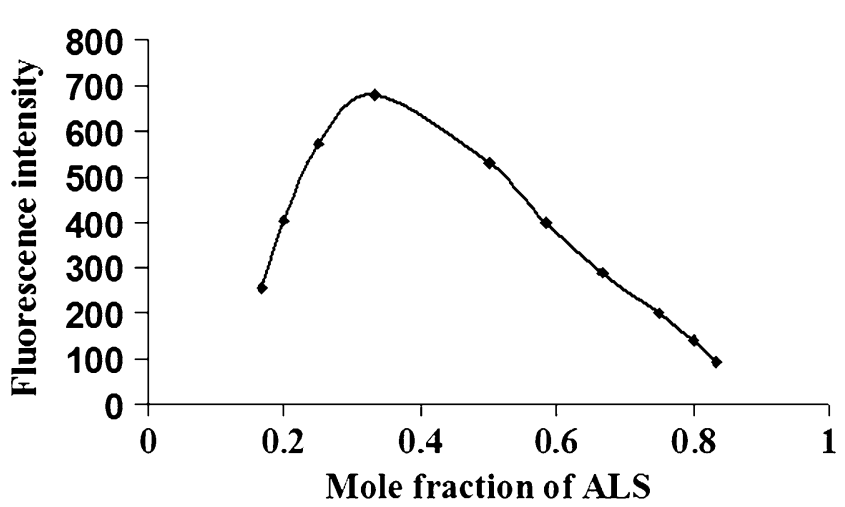

Fig. 5 Stoichiometry of the reaction between ALS and DNS-Cl adopting Job's method of continuous variation
All the procedures for blank were performed in the same manner. The corrected fluorescence intensity was measured at excitation wavelength of $378 \mathrm{~nm}$ and emission wavelength of $501 \mathrm{~nm}$ respectively.

\section{Procedure for Tablet Formulations}

Ten Tekturna tablets containing 150 and $300 \mathrm{mg}$ ALS were weighed and powdered separately. From each of the powdered tablet forms, an amount of the powder equivalent to 150 and $300 \mathrm{mg}$ ALS were transferred to $100 \mathrm{~mL}$ volumetric flasks seperately. About $50 \mathrm{~mL}$ of water was added and then extraction was performed mechanically for $1 \mathrm{~h}$. The volumes were brought to $100 \mathrm{~mL}$ with water and final solution was filtered. For both tablet solution, aliquot covering the working concentration range (cited in Table 1) was trasferred into glass tubes and analyzed separately as described under "Procedure for Calibration Curve" section.

The nominal content of the tablets was determined using the corresponding regression equations of the calibration curves.

Determination of the Stoichiometric Ratio of the Reaction

The reaction stoichiometry between ALS and DNS-Cl was determined by Job's continuous variation method. The drug solution with identical molar concentrations of reagent $\left(2.5 \times 10^{-4} \mathrm{M}\right)$ were mixed in varying volume ratios $((5: 1$, $4.8: 1.2, \ldots, 1.2: 4.8,1: 5)$ in which the total volume of the mixtures were kept at $6.0 \mathrm{~mL}$, and the procedures were completed as described for the calibration curve. The fluorescence intensity values obtained were plotted against the mole fraction of the drug solution. Each determination was carried out in triplicate.

\section{Results and Discussion}

Optimization of Experimental Parameters

The different experimental parameters affecting the development of the reaction product and its stability were studied and optimized for the spectrofluorimetric method. Such factors were changed individually while others were kept constant. These factors include $\mathrm{pH}$, type of buffer, amounts of reagent, temperature, reaction time and effect of solvent.

\section{Effect of $\mathrm{pH}$}

The influence of $\mathrm{pH}$ on the fluorescence intensity of the reaction product was examined using bicarbonate solu- 
Fig. 6 IR spectrum of ALS

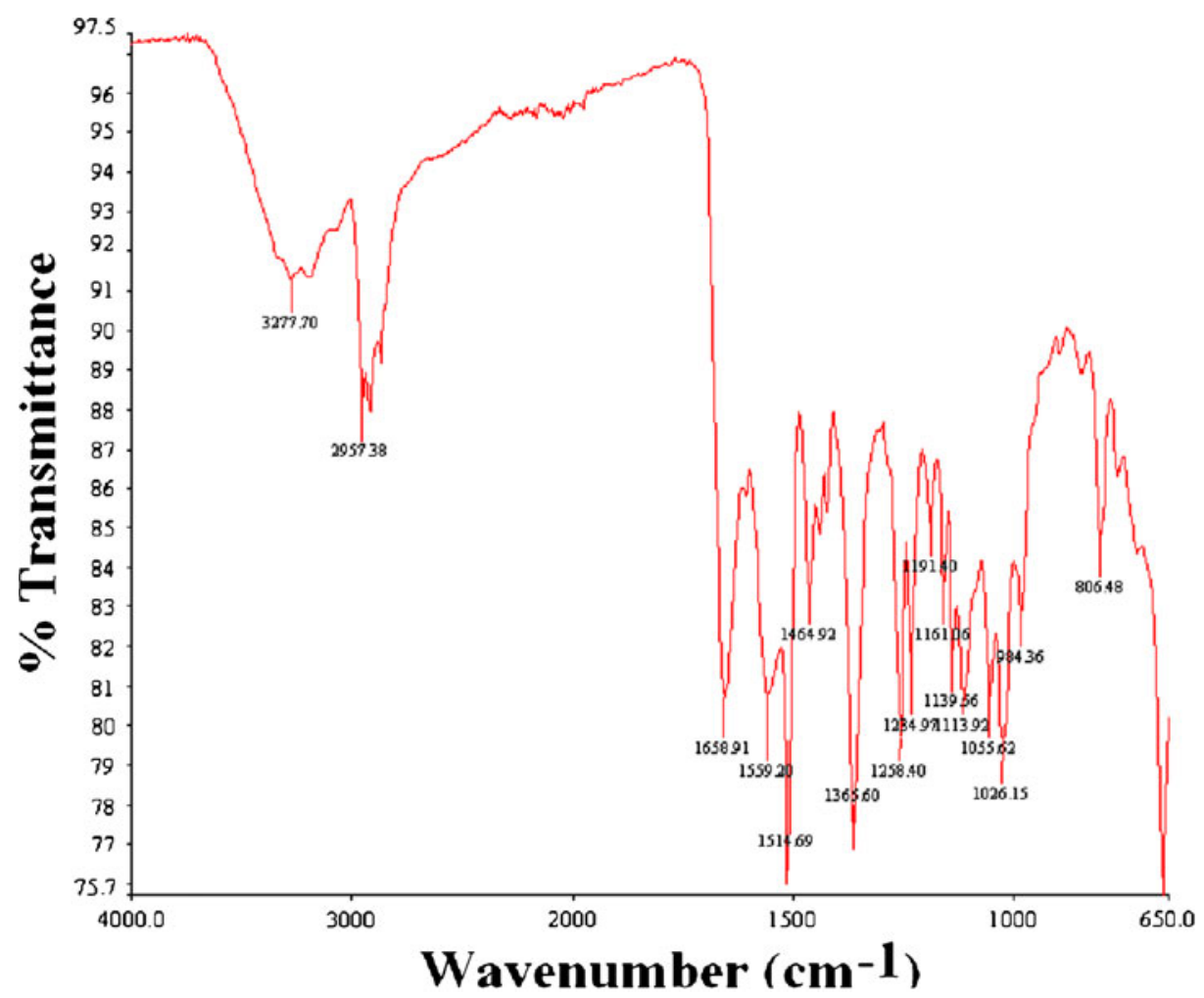

tion and borate buffer over the $\mathrm{pH}$ range from 9.2 to 11.0 since DNS-Cl reacts under alkaline conditions. The maximum fluorescence intensity was obtained when the reaction was carried out with bicarbonate solution of $\mathrm{pH}$ 10.5 (Fig. 1) and the optimum volume of this solution was $0.3 \mathrm{~mL}$.
Fig. 7 IR spectrum of derivatization of drug with DNS-Cl

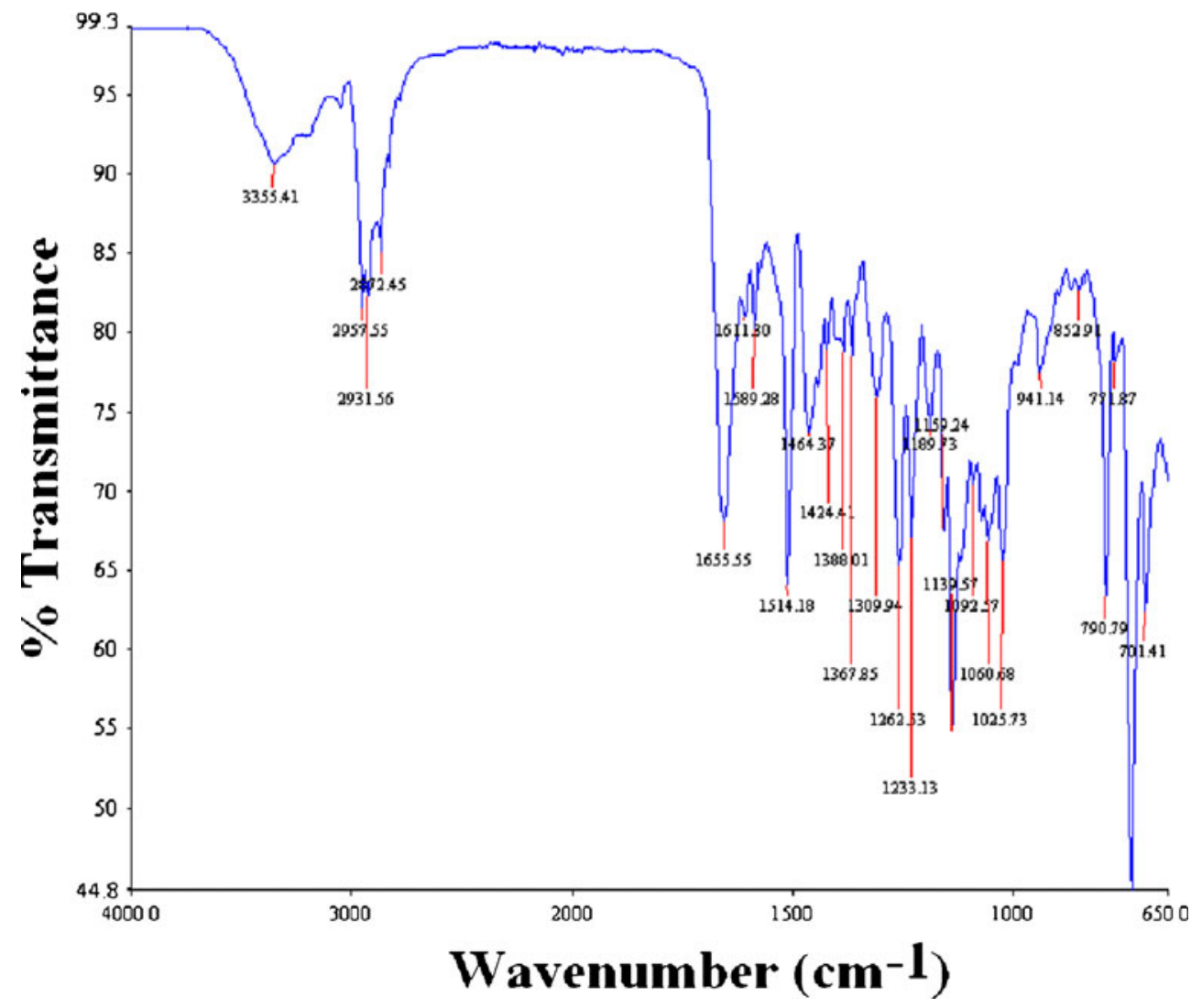


Scheme 1 Reaction scheme of ALS with DNS-Cl

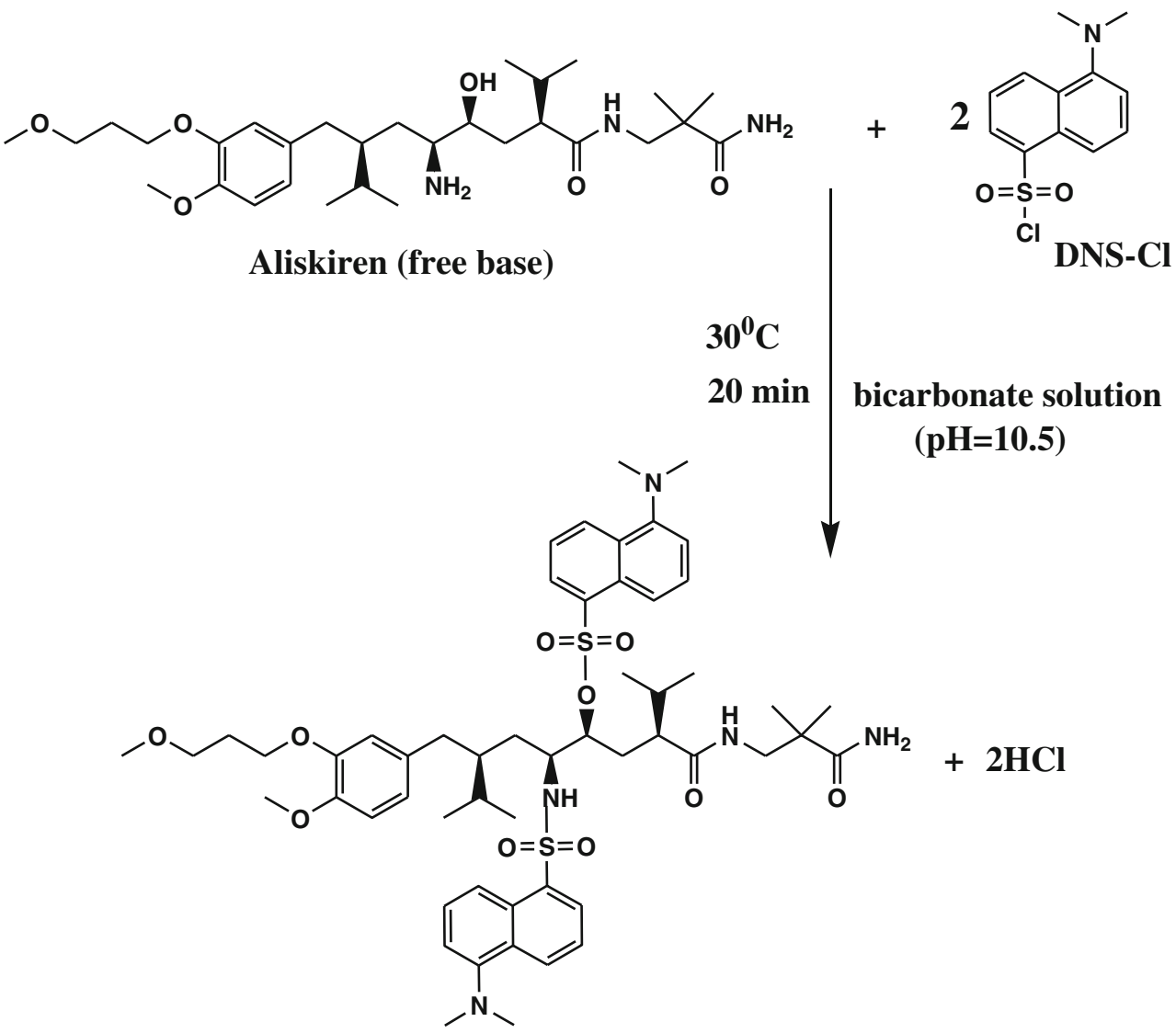

\section{Effect of DNS-Cl Concentration}

The effect of the concentration of DNS-Cl was studied using different volumes of the reagent at $2 \mathrm{mg} / \mathrm{mL}$ solution (varied from $50 \mathrm{~mL}$ to $350 \mu \mathrm{L}$ ). It was found that increasing the

Table 2 Statistical parameters for analysis of derivatives of ALS with DNS-Cl

\begin{tabular}{lll}
\hline Parameters & Standard solution & Plasma \\
\hline $\begin{array}{l}\text { Linearity range }^{\mathrm{a}} \\
(\mathrm{ng} / \mathrm{mL})\end{array}$ & $100.0-700.0$ & $50-150$ \\
$\lambda_{\mathrm{ex}} / \lambda_{\mathrm{em}}(\mathrm{nm})$ & $378 / 501$ & $378 / 501$ \\
Regression equation $^{\mathrm{b}}$ & & \\
Slope $\pm \mathrm{SD}$ & $1.0051 \pm 0.012$ & $6.9638 \pm 0.07$ \\
Intercept $\pm \mathrm{SD}_{\text {Correlation }}^{\text {coefficient }(\mathrm{r})}$ & $94.4392 \pm 9.22$ & $-216.86 \pm 10.79$ \\
LOD $(\mathrm{ng} / \mathrm{mL})$ & 0.9998 & 0.9986 \\
LOQ $(\mathrm{ng} / \mathrm{mL})$ & 27.53 & 4.91 \\
\hline
\end{tabular}

${ }^{a}$ Average of six and five determinations for the drug in standard solution and plasma, respectively

${ }^{\mathrm{b}} n=5$ Correspond to replicate analysis for each level

${ }^{b} I_{\mathrm{f}}=\mathrm{aC}+\mathrm{b}$ (where $\mathrm{C}$ is the concentration of the drug in $\mathrm{ng} / \mathrm{mL}, \mathrm{I}_{\mathrm{f}}$ is the fluorescence intensity at emission wavelength volume of the reagent produces a proportional increase in the fluorescence intensity of the reaction product up to $300 \mu \mathrm{L}$. However, no further increase in the fluorescence intensity was observed upon increasing the volume of the reagent up to $350 \mu \mathrm{L}$. Therefore, $300 \mu \mathrm{L}$ of $2 \mathrm{mg} / \mathrm{mL}$ of DNS-Cl solution was chosen for derivatization reaction.

\section{Effect of Reaction and Heating Time}

Different reaction times $(5-30 \mathrm{~min})$ and temperatures (at room and $30-60{ }^{\circ} \mathrm{C}$ ) were studied to obtain highest fluorescence intensity of the reaction product. It was found that the reaction product reached the highest fluorescence within $20 \mathrm{~min}$ at $30{ }^{\circ} \mathrm{C}$. The effect of temperature on the reaction of ALS with DNS-Cl was shown in Fig. 2.

\section{Effect of Extraction Solvent}

In order to avoid the interference of the highly fluorescent dansyl hydroxide formed in the dansylation reaction medium, which is polar character and remains in the aqueous phase, the derivatization product was extracted with immiscible organic solvent for spectrofluorimetric method. For this purpose, different solvents including tetrachloromethane, diethyl ether, dichloromethane and 
Table 3 Recovery of ALS from standard samples and plasma $(n=5)$

\begin{tabular}{lccc}
\hline Amount added $(\mathrm{ng} / \mathrm{mL})$ & Amount found $(\mathrm{ng} / \mathrm{mL})($ Mean $\pm \mathrm{SD})$ & Recovery $(\%)$ & RSD $(\%)$ \\
\hline Standard preparation & & & \\
200.0 & $201.38 \pm 5.51$ & 101.37 & 2.73 \\
400.0 & $402.66 \pm 7.88$ & 101.33 & 1.96 \\
600.0 & $599.26 \pm 5.95$ & 99.75 & 0.99 \\
Plasma & & & \\
50.0 & $48.04 \pm 2.52$ & 96.08 & 2.14 \\
100.0 & $98.59 \pm 4.62$ & 98.59 & 0.98 \\
150.0 & $148.13 \pm 4.51$ & 98.75 & 0.55 \\
\hline
\end{tabular}

chloroform were tested and the highest fluorescence was obtained upon using dichloromethane (Table 1). The emission and excitation spectrum of derivatization product of ALS in dichloromethane are shown in Figs. 3 and 4. The fluorescence intensity of the derivatization product in the same solvent was stable for at least $24 \mathrm{~h}$ if stored in dark at room temperature.

\section{Stoichiometry and Mechanism of the Reaction}

Under the selected conditions, the stoichiometry of the reaction between ALS and DNS-Cl was studied by Job's method of continuous variation [18]. As shown in Fig. 5, the stoichiometry of the reaction was found as 1:2 ratios (drug/reagent), confirming that one molecule of ALS reacts with two molecule of DNS-Cl.

ALS contains a primary aliphatic amine and secondary hydroxyl group which are capable of acting as base and involved nucleophilic reactions. Thus, the sulfonyl chloride group of $\mathrm{DNS}-\mathrm{Cl}$ can be attacked by these nucleophilic groups. Also, the acidity of these groups plays an important factor in the dansylation reaction. Comparison of acidity based on pKa appears as follows: R-NH2 (pKa 36), ROH (pKa 16), RNHR (pKa 11) [13]. Based on all these fact and by the previous dansylation studies, it is concluded that ALS in alkaline medium $(\mathrm{pH}=10.5)$ reacts with DNS-Cl through its primary amino group and hydroxyl group. In order to confirm the placement of dansyl moiety on drug, IR spectra (Perkin-Elmer Universal ATR sampling accessory apparatus) of ALS (Fig. 6) and derivatization product (Fig. 7) which was prepared as the same manner of described in experimental section were also recorded and compared. IR spectrum did not provide more information

Table 4 Results obtained for ALS determination in Tekturna tablets $(n=6)$

\begin{tabular}{lccc}
\hline Labelled amount & Mean \pm SD & Recovery (\%) & RSD (\%) \\
\hline 150 mg ALS & $150.27 \pm 0.96$ & 100.18 & 0.64 \\
300 mg ALS & $300.16 \pm 1.05$ & 100.03 & 0.35 \\
\hline
\end{tabular}

since several absorption bands for the stretching of $\mathrm{O}-\mathrm{H}$ and $\mathrm{N}-\mathrm{H}$ bonds were observed in the same regions. However, the extinction of characteristic $\mathrm{O}-\mathrm{H}$ signal at $1,284 \mathrm{~cm}^{-1}$ [19] in the IR spectrum of the reaction product provided that one DNS moiety was attached to the drug molecule at hydroxyl group.

A schematic proposal of the reaction pathway is given in Scheme 1.

\section{Analytical Performance}

\section{Linearity and Sensitivity}

For evaluation of linearity at the selected conditions, determination of ALS was carried out at six concentration $(n=6)$ and five concentration levels for standard solution and plasma samples $(n=5)$, respectively. The calibration curves of ALS were linear over the concentration range of $100-700 \mathrm{ng} / \mathrm{mL}$ for standard solution and $50-150 \mathrm{ng} / \mathrm{mL}$ for plasma samples.

The limit of detection (LOD) and limit of quantification (LOQ) were calculated as $3 S_{b} / \mathrm{m}$ and $10 S_{b} / \mathrm{m}$, respectively, $S_{b}$ is the standard deviation of the intercept of regression line, and $\mathrm{m}$ is the slope of the calibratiom curve [20]. On this basis, the LOD and LOQ of the proposed method for standard drug analysis were 27.53 and $91.76 \mathrm{ng} / \mathrm{mL}$ for ALS, respectively. The LOD and LOQ for plasma samples were 4.91 and 16.37 , respectively. The parameters for the analytical performance of the proposed method are summarized in Table 2.

\section{Accuracy and Precision}

Accuracy, intraday and interday precisions of the method were determined. Five replicate spiked plasma samples in the same day, as well as on five consecutive days were assayed for intra-day and inter-day accuracy at three different concentrations for each analyte. Accuracy was calculated as deviation of the mean from the nominal concentration. The intraday and interday precisions (expressed as the relative standard deviation (RSD\%) for 
ALS ranged from 0.47 to $2.51 \%$ and 0.58 to $2.19 \%$, respectively. The intraday and interday precisions for drug in plasma ranged from 0.37 to $2.09 \%$ and 0.96 to $2.30 \%$, respectively.

\section{Recovery}

Recovery studies were carried, by spiking known different amounts of pure drug solutions to the preanalysed drug samples. The results given in Table 3 revealed that the RSD $\%$ and percent average of recovery for preparation samples were in the range of $0.99-2.73 \%, 99.75-101.37 \%$. Recovery results suggest method to be unaffected in the presence of formulation excipients and confirm the heigh accuracy.

The RSD\% and percent average of extraction recovery for ALS determined at different concentrations in plasma were in the range of $0.55-2.14 \%, 96.08-98.75 \%$, respectively (Table 3).

\section{Robustness}

Robustness was examined by evaluating the influence of small variations in the experimental conditions such as working excitation and emission wavelengths $( \pm 3 \mathrm{~nm})$, volume of reagent $( \pm 5 \mu \mathrm{L})$, volume of bicarbonate solution $( \pm 10 \mu \mathrm{L})$, change in $\mathrm{pH}( \pm 0.2)$, the temperature degree and heat time, which are applied for derivatization reaction $\left( \pm 5^{\circ} \mathrm{C}\right.$ and $\pm 5 \mathrm{~min}$ ). These minor changes that may take place during the experimental operation did not have any significant effect on fluorescence intensity of the reaction product. $\mathrm{RSD} \%$ for the measured fluorescence intensity after the studied variations did not exceed $4.50 \%$.

\section{Application to Tablets}

The proposed method was successfully applied to analysis of two different commercial tablets (Tekturna Tablets) which contain 150 and $300 \mathrm{mg}$ ALS. The mean recovery values of tablets that were contained $150 \mathrm{mg}$ and $300 \mathrm{mg}$ ALS were $100.18 \%$ and $100.03 \%$, respectively (Table 4 ).

\section{Conclusion}

The proposed spectrofluorimetric method has the advantage of being simple, fast, highly sensitive, accurate, low cost, and do not require any pretreatment of the drug and tedious extraction procedure. The method was successfuly applied for determining ALS in tablets and spiked plasma without any interference from excipients. Therefore, the developed method can be suitable for routine analysis of ALS in quality control laboratories and clinical laboratories.
Acknowledgement This work was supported by Research Fund of the Istanbul University. Project number: BAP-4045.

Open Access This article is distributed under the terms of the Creative Commons Attribution Noncommercial License which permits any noncommercial use, distribution, and reproduction in any medium, provided the original author(s) and source are credited.

\section{References}

1. Huang HL, Vaidyanathan S, Yeh CM, Bizot MN, Dieterich HA, Dole WP, Howard D. Effect of aliskiren, an oral direct renin inhibitor, on the pharmacokinetics and pharmacodynamics of a single dose of acenocoumarol in healthy volunteers. Curr Med Res Opin 24:2449-2456

2. Limoges D, Dieterich HA, Yeh CM, Vaidyanathan S, Howard D, Dole WP (2008) A study of dose-proportionality in the pharmacokinetics of the oral direct renin inhibitor aliskiren in healthy subjects. Int J Clin Pharmacol Ther 46:252-258

3. Zhao C, Vaidyanathan S, Yeh CM, Maboudian M, Armin Dieterich H (2006) Aliskiren exhibits similar pharmacokinetics in healthy volunteers and patients with type 2 diabetes mellitus. Clin Pharmacokinet 45:1125-1134

4. Lefévre G, Duval M, Poncin A (2000) Direct microradioimmunoassay of the new rennin inhibitor CGP 60536. J Immunoassay 21:65-84

5. Lefevre G, Gauron S (2000) Automated quantitative determination of the new rennin inhibitor CGP 60536 by high-performance liquid chromatography. J Chromatogr B 738:129-136

6. Dieterle W, Corynen S, Vaidyanathan S, Mann J (2005) Pharmacokinetic interactions of the oral renin inhibitor aliskiren with lovastatin, atenolol, celecoxib and cimetidine. Int $\mathrm{J}$ Clin Pharmacol Ther 43:527-535

7. Vaidyanathan S, Valencia J, Kemp C, Zhao C, Yeh CM, Bizot MN, Denouel J, Dieterich HA, Dole WP (2006) Lack of pharmacokinetic interactions of aliskiren, a novel direct rennin inhibitor for the treatment of hypertension, with the antihypertensives amlodipine, valsartan, hydrochlorothiazide (HCTZ) and ramipril in healthy volunteers. Int $\mathrm{J}$ Clin Pract 60:1343-1356

8. Ayalasomayajula S, Tchaloyan S, Yeh CM, Bizot MN, Dieterich HA, Howard D, Dole WP (2008) A study of the pharmacokinetic interactions of the direct renin inhibitor aliskiren with allopurinol, celecoxib and cimetidine in healthy subjects. Curr Med Res Opin 224:717-726

9. Vaidyanathan S, Bigler H, Yeh C, Bizot MN, Dieterich HA, Howard D, Dole WP (2007) Pharmacokinetics of the oral direct renin inhibitor aliskiren alone and in combination with irbesartan in renal impairment. Clin Pharmacokinet 46:661675

10. Wrasse-Sangoi M, Secretti LT, Diefenbach IF, Rolim CMB, Sangoi MD (2010) Development and validation of an UV spectrophotometric method for the determination of aliskiren in tablets. Quim Nova 33:1330-1334

11. Pachauri S, Paliwal S, Srinivas KS, Singh Y, Jain V (2010) Development and validation of HPLC method for analysis of some antihypertensive agents in their pharmaceutical dosage forms. J Pharm Sci Res 2:459-464

12. AyadMM,el-HayMH(1984)Spectrofluorimetricmicro-determination of imidazoline derivatives using 1-dimethylaminonaphthalene-5sulphonyl chloride. Analyst 109:1431-1434

13. Bartzatt R (2003) Dansylation of aromatic, aliphatic and medicinal carboxylic acid compounds in $1 \mathrm{M} \mathrm{Na} \mathrm{CO}_{3}$ buffer. Anal Chim Acta 488:203-209 
14. Ma Y, Xiang F, Jin W, Yu L (2010) Determination of total glutathione in yeasts by highperformance liquid chromatography with dansylation. Z Naturforsch C 65:391-394

15. El-Enany N, Belal F, Rizk M (2008) Spectrofluorimetric determination of oxamniquine in dosage forms and spiked human plasma through derivatization with 1 dimethylaminonaphthalene-5sulphonyl chloride. J Fluoresc 18:349-355

16. Zhuang XM, Yuan M, Zhang ZW, Wang XY, Zhang ZQ, Ruan JX (2008) Determination of 4-dimethylaminophenol concentrations in dog blood using LC-ESI/MS/MS combined with precolumn derivatization. J Chromatogr B Analyt Technol Biomed Life Sci 876:76-82
17. Cruces-Blanco C, Segura Carretero A, Merino Boyle E, Fernández GA (1999) The use of dansyl chloride in the spectrofluorimetric determination of the synthetic antioxidant butylated hydroxyanisole in foodstuffs. Talanta 50:1099-1108

18. Job P (1928) Formation and stability of inorganic complexes in solution. Anal Chem 9:113-203

19. Coates, J. (2000). Encyclopedia of analytical chemistry: interpretation of infrared spectra, a practical approach. R.A. Meyers (Ed.), John Wiley and Sons Ltd, Chichester. pp. 10815-10837

20. Validation of Analytical Procedures. Methodology ICH harmonised tripartite guideline having reached step 4 of the ICH process at the ICH Steering Committee Meeting on, 1996, November 6 